\begin{tabular}{|l|l|l|c|c|}
\hline Clinical Study & $\begin{array}{l}\text { R A Alwani, L W Schmit } \\
\text { Jongbloed and others }\end{array}$ & Differentiating CS and PCS & 170:4 & 477-486 \\
\cline { 2 - 4 }
\end{tabular}

\title{
Differentiating between Cushing's disease and pseudo-Cushing's syndrome: comparison of four tests
}

\author{
R A Alwani", L W Schmit Jongbloed", F H de Jong, A J van der Lely, \\ W W de Herder and R A Feelders
}

Division of Endocrinology, Room H555, Department of Internal Medicine, Erasmus Medical Centre, PO Box 2040, 3000 CA Rotterdam, The Netherlands

${ }^{*}$ (R A Alwani and L W Schmit Jongbloed contributed equally to this work)

\author{
Correspondence \\ should be addressed \\ to R A Alwani \\ Email \\ r.alwani@erasmusmc.nl
}

\begin{abstract}
Objective: To evaluate the diagnostic performance of four different tests in order to differentiate between Cushing's disease (CD) and pseudo-Cushing's syndrome (PCS).

Methods: In this prospective study, a total of 73 patients with clinical features of hypercortisolism and insufficient suppression of serum cortisol after $1 \mathrm{mg}$ overnight dexamethasone and/or an elevated excretion of cortisol in 24-h urine samples were included. The circadian rhythm of serum cortisol levels as well as midnight serum cortisol (MserC) levels were assessed in all 73 patients. Late-night salivary cortisol (LNSC) concentrations were obtained in 44 patients. The dexamethasone-CRH (Dex-CRH) test was performed in 54 patients.

Results: Fifty-three patients were diagnosed with $C D$ and subsequently treated. Twenty patients were classified as having PSC. Serum cortisol circadian rhythm: the diurnal rhythmicity of cortisol secretion was retained in PCS. A cortisol midnight:morning ratio of $>0.67$ is highly suggestive of $C D$ (positive predictive value (PPV) $100 \%$ and negative predictive value (NPV) $73 \%$ ). MserC concentration $>243 \mathrm{nmol} / \mathrm{l}$ has a PPV of $98 \%$ in predicting true CD (NPV 95\%). LNSC level

$>9.3 \mathrm{nmol} / \mathrm{l}$ predicted CD in $94 \%$ of patients (NPV 100\%). Dex-CRH test: after 2 days of dexamethasone suppression, a $\mathrm{CRH}$-stimulated cortisol level $>87 \mathrm{nmol} / \mathrm{l}(T=15 \mathrm{~min})$ resulted in a PPV of $100 \%$ and an NPV of $90 \%$.

Conclusion: The Dex-CRH test as well as a single measurement of cortisol in serum or saliva at late (mid-) night demonstrated high diagnostic accuracy in differentiating PCS from true CD.

European Journal of Endocrinology (2014) 170, 477-486
\end{abstract}

\section{Introduction}

Cushing's disease (CD) is caused by an adrenocorticotropin (ACTH)-secreting pituitary adenoma leading to chronic overproduction of cortisol. This results in a clinical phenotype with features like a full plethoric face, central obesity, and muscle and skin atrophy. The diagnosis can be difficult due to gradual development of symptoms and due to overlap with features of metabolic syndrome (1). In addition, it can be challenging to differentiate cases

(C) 2014 European Society of Endocrinology Printed in Great Britain with mild ACTH-dependent hypercortisolism from conditions that are accompanied by (physiologic) overactivity of the hypothalamic-pituitary-adrenal axis referred to as pseudo-Cushing's syndrome (PCS). PCS can present with a similar clinical phenotype and is associated with chronic alcoholism, psychiatric disorders, severe obesity, poorly controlled diabetes, and extreme physical stress. Treatment of these underlying conditions will lead

Published by Bioscientifica Ltd. 
to resolution of the Cushingoid symptoms $(1,2)$. Appropriate classification of CD and PCS is important as untreated $\mathrm{CD}$ is associated with significant morbidity and mortality while wrongly diagnosed patients may experience negative side effects of needless therapy $(3,4)$. The $1 \mathrm{mg}$ overnight dexamethasone suppression test (DST) and the excretion of free cortisol in 24-h urinary samples (urinary free cortisol (UFC)) are widely used in the initial evaluation of patients with suspected hypercortisolism. In recent years, assessment of late-night salivary cortisol (LNSC) is increasingly being used as a first-line screening test $(1,5,6)$. However, first-line screening tests are not always able to differentiate accurately between $C D$ and PCS $(2,7,8)$. The substantial overlap in test results has resulted in the development of several second-line tests. The midnight serum cortisol (MserC) test, the analysis of serum cortisol circadian rhythm and the dexamethasonecorticotropin-releasing hormone test (Dex-CRH) are examples of second-line tests that are currently used in medical practice $(6,9,10)$. Both MserC and LNSC as well as the assessment of serum cortisol circadian rhythm are based on the assumption that patients with CD lose their normal cortisol diurnal pattern and show persistently elevated cortisol levels throughout the day, while patients with PCS retain their normal, although slightly elevated rhythm, reaching maximum levels in the morning and minimum levels at midnight $(9,11,12)$.

The Dex-CRH test is based on the fact that patients with $\mathrm{CD}$ are still able to mount a pituitary-adrenal response after administration of exogenous $\mathrm{CRH}$ despite pre-treatment with dexamethasone. Patients with PCS, however, are relatively unresponsive to $\mathrm{CRH}$ stimulation when suppressed by dexamethasone (10).

Currently, the Dex-CRH test and the measurement of MserC are often regarded as the preferred tests to diagnose or exclude PCS. However, there has been considerable debate regarding the diagnostic performance and optimal cut-off values $(1,9,13,14,15,16,17)$. The objective of our study was to prospectively validate four tests (LNSC, serum cortisol circadian rhythm, MserC, and Dex-CRH) in the same cohort of patients.

\section{Subjects and methods}

\section{Patients}

Between 1999 and 2011, a total of 73 patients, suspected for CD or PCS, were prospectively analyzed in the Erasmus Medical Centre Rotterdam (The Netherlands). All patients showed clinical features suggesting hypercortisolism and all of them had positive first-line screening tests defined as insufficient suppression of serum cortisol after DST and/or elevated UFC (mean of at least two 24-h urinary collections). No patients were taking anticonvulsants. When used, estrogens and glucocorticoid-containing preparations were stopped at least 6 weeks before the tests. Because the differentiation between PCS and CS involves mostly differentiation from CD, patients with suppressed ACTH levels (suggesting an adrenal cause of hypercortisolism) and patients with ectopic ACTH secretion (usually a different clinical presentation) were excluded from this study.

Fifty-three patients (ten males, 43 females, mean age $45.9 \pm 2.0$ years) were ultimately classified as having true CD. The diagnosis of CD was verified by histological examination of the surgically resected pituitary adenoma (basophilic adenomas with positive ACTH staining) and by resolution of symptoms after pituitary surgery and/or fractionated stereotactic radiotherapy. The majority of patients with $\mathrm{CD}$ had microadenomas (66\%). The remaining 20 patients (six males, 14 females, mean age $47.7 \pm 3.2$ years) were classified as having PCS. None of them had undetectable ACTH levels or abnormal pituitary findings on magnetic resonance imaging. Severe obesity with or without polycystic ovary syndrome were the most common diagnoses in the PCS group $(n=7)$. Other diagnoses included depression $(n=6)$, chronic alcoholism $(n=5)$ and underlying illnesses such as heart failure $(n=1)$, and cirrhosis of the liver $(n=1)$. The prevalence of Cushingoid features in patients with PCS is shown Fig. 1. Fourteen patients with PCS had normalization of cortisol levels after successful treatment of their underlying conditions (cessation of alcohol, treatment of mood disorder, and achievement of significant weight loss). All patients with PCS showed no progression of symptoms (moon face, buffalo hump, striae, hirsutism, acne, and myopathy) during the median follow-up period of 56 months (range 12-146 months). Clinical characteristics of patients with CD and patients with PCS are detailed in Table 1. This study was approved by the Local Institutional Review Board. Informed consent was obtained from all patients.

\section{First-line screening tests}

All 73 patients collected at least two 24-h urinary samples on different days in order to determine the excretion of free cortisol (UFC, cut-off $>850 \mathrm{nmol} / 24 \mathrm{~h}$ ). All 73 patients also underwent the 1-mg DST. The test was performed within 1-7 days after collection of 24-h urine 


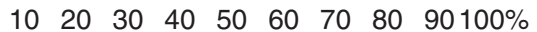

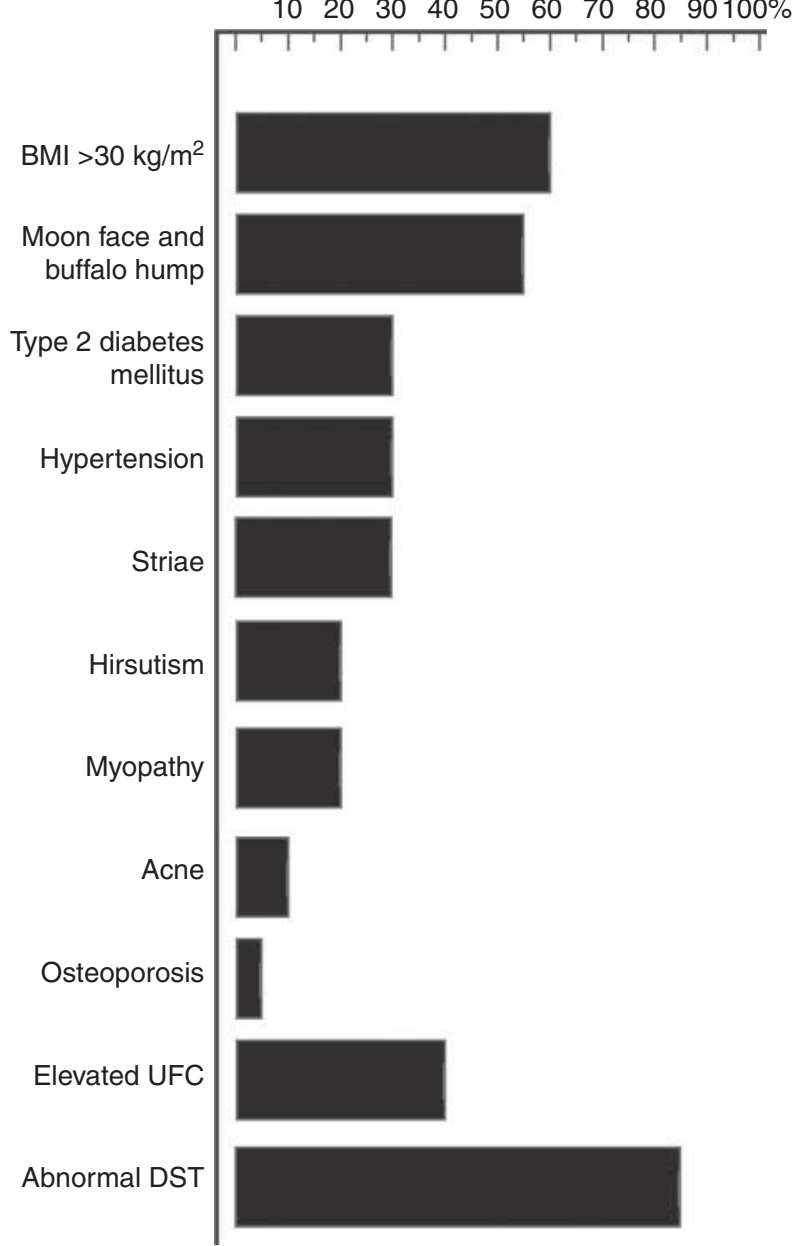

\section{Figure 1}

Block diagram showing the prevalence of various Cushingoid features in 20 patients with pseudo-Cushing's syndrome.

samples. An oral dose of $1 \mathrm{mg}$ dexamethasone was administered at $2300 \mathrm{~h}$, followed by assessment of serum cortisol at $0800 \mathrm{~h}$ (cut-off value $>50 \mathrm{nmol} / \mathrm{l}$ ). Both firstline screening tests (DST and UFC) were done in an outpatient setting. Mean post-dexamethasone cortisol values and UFC levels are shown in Table 1. All 53 patients with CD showed insufficient suppression of serum cortisol after the $1 \mathrm{mg}$ DST. UFC levels were elevated in $79 \%$ of CD patients. In 42 patients with CD, both first-line screening tests (DST and UFC) noted abnormal test results. In the PCS group, $85 \%$ of patients showed insufficient suppression of serum cortisol after dexamethasone suppression. UFC levels were elevated in $40 \%$ of PCS patients $(n=8)$. In five patients with PCS, both first-line screening tests noted abnormal test results.

\section{Second-line tests}

The second-line tests were performed within 2 weeks after completion of the first-line screening tests. During this period, there was no change in co-morbidity, used medications or alcohol consumption. All tests were carried out within 1 week after admission to the hospital. Patients were restricted to bed rest. For assessment of MserC and circadian rhythm of cortisol, serum was obtained at 0900 , 1700,2200 , and $2400 \mathrm{~h}$ in wakeful patients, using an indwelling venous catheter placed one day in advance. The cortisol midnight:morning ratio was defined as serum cortisol concentration at $2400 \mathrm{~h}$ /serum cortisol concentration at $0900 \mathrm{~h}$. The Dex-CRH test was added to the study protocol from 2003 onwards. The Dex-CRH test was performed as described previously by Yanovski et al. (10). In short, patients received $0.5 \mathrm{mg}$ dexamethasone orally, every $6 \mathrm{~h}$ for 2 days, starting at $1200 \mathrm{~h}$. This was followed by i.v. administration of $1 \mu \mathrm{g} / \mathrm{kg}$ human CRH (Ferring BV) $2 \mathrm{~h}$ after the last administration of dexamethasone. Serum cortisol and plasma ACTH levels were measured 15 and 1 min before $\mathrm{CRH}$ administration and 5, 15, 30, 45, and 60 min after CRH administration. Salivary cortisol assessment was performed from 2007 onwards. For assessment of LNSC, saliva was obtained simultaneously with serum using a commercially-available swab (Salivette, Sarstedt AG \& Co., Nümbrecht, Germany). This cotton swab was chewed for $1 \mathrm{~min}$ and stored in a double chamber plastic tube at room temperature. Before obtaining the sample, subjects were instructed not to drink, smoke, eat or brush their teeth for at least $2 \mathrm{~h}$.

Table 1 Patient characteristics and first- and second-line test results of 53 patients with Cushing's disease (CD) and 20 patients with pseudo-Cushing's syndrome (PCS).

\begin{tabular}{|c|c|c|}
\hline & CD & PCS \\
\hline Mean age (years) & $45.9 \pm 2.0$ & $47.7 \pm 3.2$ \\
\hline Male & 10 & $\overline{6}$ \\
\hline Female & 43 & 14 \\
\hline $\begin{array}{l}\text { Serum cortisol after overnight } 1 \mathrm{mg} \\
\text { dexamethasone (nmol/l) }\end{array}$ & $439 \pm 39$ & $173 \pm 52$ \\
\hline Urinary free cortisol (nmol/24 h) & $3371 \pm 1027$ & $698 \pm 104$ \\
\hline Range & $187-\overline{14} 585$ & $152-1501$ \\
\hline \multicolumn{3}{|l|}{ Circadian rhythm, serum (nmol/l) } \\
\hline $0900 \mathrm{~h}$ serum cortisol & $641 \pm 40$ & $418 \pm 43$ \\
\hline $1700 \mathrm{~h}$ serum cortisol & $601 \pm 41$ & $283 \pm 24$ \\
\hline 2200 h serum cortisol & $544 \pm 38$ & $180 \pm 32$ \\
\hline $2400 \mathrm{~h}$ serum cortisol & $577 \pm 43$ & $141 \pm 13$ \\
\hline Midnight salivary cortisol (nmol/l) & $35.0 \pm 6.4$ & $7.7 \pm 1.0$ \\
\hline \multicolumn{3}{|l|}{ Dexamethasone-CRH test $(\mathrm{nmol} / \mathrm{l})$} \\
\hline Cortisol before $\mathrm{CRH}$ & $288 \pm 51$ & $35 \pm 3.0$ \\
\hline Cortisol 15 min after $\mathrm{CRH}$ & $365 \pm 43$ & $41 \pm 4.5$ \\
\hline
\end{tabular}




\section{Laboratory assays}

Serum and urinary cortisol and plasma ACTH were measured using chemiluminescence-based immunoassays (Immulite 2000, Siemens, Los Angeles, CA, USA; inter- and intra-assay coefficients of variation, respectively below 15 and 7\% for cortisol and below 6.5 and $5.5 \%$ for ACTH). Urinary cortisol was measured without prior solvent extraction. Although this may be a less accurate method, the upper limit of normal of this in-house assay was carefully determined according to cortisol secretion rate in healthy controls (18). Salivary cortisol was measured using a commercial kit (Salivary Cortisol ELISA SLV-2930, DRG Instruments $\mathrm{GmbH}$, Marburg, Germany).

\section{Statistical analysis}

Mean and s.E.M. were calculated for continuous data and presented as mean \pm s.E.M. Proportions were calculated for categorical data. We considered a $P$ value of $<0.05$ to be statistically significant. The two-tailed Student's $t$-test was used when continuous data were normally distributed. The Mann-Whitney $U$ test was used when continuous data were not normally distributed. Sensitivity, specificity, positive predictive value (PPV), and negative predictive value (NPV) were calculated for each test using standard methods. PPV was defined as the proportion of patients that are correctly diagnosed with CD. NPV was defined as the proportion of patients that are correctly diagnosed with PCS. Receiver operating characteristic (ROC) curves were used for each test to determine the area under the curve (AUC) and to define the cut-off value with the best diagnostic performance by minimizing the absolute difference between the highest PPV and highest NPV (diagnostic accuracy of the test). The leave-one-out cross validation method was used to see if a combination of the MserC measurement with the Dex-CRH test would further increase the discriminatory power to distinguish patients with true CD from patients with PCS. Statistical analysis and graphing were performed with the commercially available software packages GraphPad Prism, version 3.0 (GraphPad Software, San Diego, CA, USA) and MedCalc, version 9.64 (MedCalc Software, Ostend, Belgium).

\section{Results}

\section{Cortisol circadian rhythm}

The dynamics of cortisol secretion in serum were investigated in 52 patients with $\mathrm{CD}$ and in 19 patients with PCS. Patients with CD had higher mean cortisol values at all time points compared with patients with PCS. Also, patients with $\mathrm{CD}$ showed a relatively flat cortisol pattern throughout the day, whereas patients with PCS retained a diurnal rhythmicity of cortisol secretion (Table 1 and Fig. 2). ROC curve analysis (Fig. 2) showed a cortisol midnight:morning ratio of 0.67 to have the highest discriminating capacity between the diagnoses of CD and PCS (PPV 100\%, NPV 73\%, and AUC $=0.969$ ). The cortisol midnight:morning ratio was $>0.67$ in 45 patients with CD (sensitivity $87 \%$ ), whereas all patients with PCS noted a ratio of $\leq 0.67$ (specificity 100\%).

The serum cortisol late afternoon:morning ratio (cortisol $1700 \mathrm{~h}$ :cortisol $0900 \mathrm{~h}$ ) and the analysis of the circadian rhythm in salivary cortisol and plasma ACTH did not improve discrimination between groups and are therefore not shown.

\section{Midnight serum cortisol}

MserC concentrations were obtained in 53 patients with $\mathrm{CD}$ and 20 patients with PCS. Mean MserC levels were significantly higher in patients with $\mathrm{CD}(577 \mathrm{nmol} / \mathrm{l} \pm 43)$ than in patients with PCS $(141 \mathrm{nmol} / 1 \pm 13)(P<0.001)$.

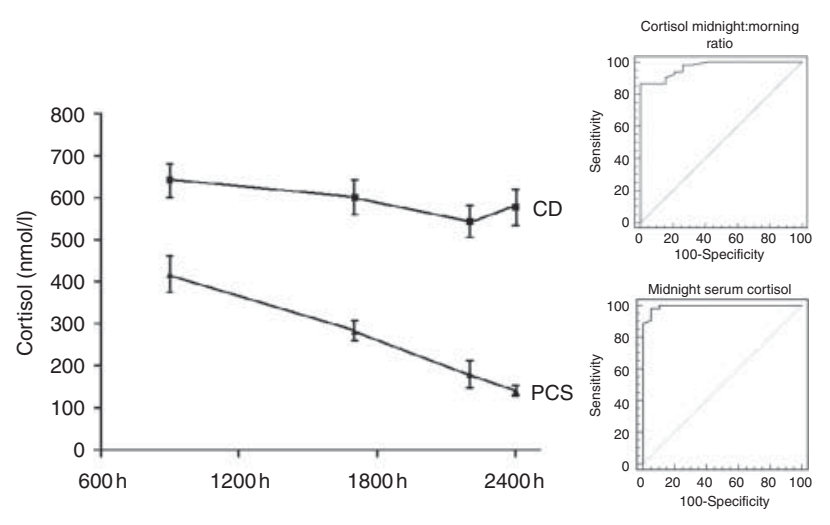

\section{Figure 2}

(Left) Mean cortisol levels in serum throughout the day of 52 patients with Cushing's disease (CD) and 19 patients with pseudo-Cushing's syndrome (PCS). (Right, top) Receiver operating characteristic (ROC) curve of the cortisol midnight: morning ratio in serum. Optimal cut-off value $=0.67$. Area under ROC curve (AUC) $=0.969$ (sensitivity $87 \%$, specificity $100 \%$, positive predictive value (PPV) $100 \%$, and negative predictive value (NPV) 73\%). (Right, bottom) ROC curve of the midnight serum cortisol concentration. Optimal cut-off value $=243 \mathrm{nmol} / \mathrm{l}$. AUC $=0.994$ (sensitivity $98 \%$, specificity $95 \%$, PPV $98 \%$, and NPV 95\%). 
The ROC curve for MserC is shown in Fig. 2. The optimal threshold value to detect true CD was $243 \mathrm{nmol} / \mathrm{l}$ (PPV 98\%, NPV 95\%, and AUC=0.994). All CD patients except one showed MserC levels in excess of $243 \mathrm{nmol} / 1$ (sensitivity 98\%). Nineteen out of 20 patients with PCS recorded MserC levels of $\leq 243 \mathrm{nmol} / 1$ (specificity 95\%).

\section{Late-night salivary cortisol}

Cortisol in saliva was measured in 33 patients with CD and 11 patients with PCS (Fig. 3). Mean LNSC levels were significantly higher $(P<0.001)$ in the $\mathrm{CD}$ group $(35.0 \pm$ $6.4 \mathrm{nmol} / \mathrm{l})$ than in the PCS group $(7.7 \pm 1.0 \mathrm{nmol} / \mathrm{l})$.

According to the ROC curve (Fig. 3), the cut-off value yielding the best PPV and NPV was $9.3 \mathrm{nmol} / \mathrm{l}$ (AUC= 0.962 ). This value corresponds to a sensitivity of $100 \%$, a specificity of $83 \%$, a PPV of $94 \%$, and an NPV of $100 \%$.

\section{Dex-CRH test}

The Dex-CRH test was performed in 35 patients with CD and 19 patients with PCS. Sixteen out of 19 patients with PCS had suppressed levels of serum cortisol below

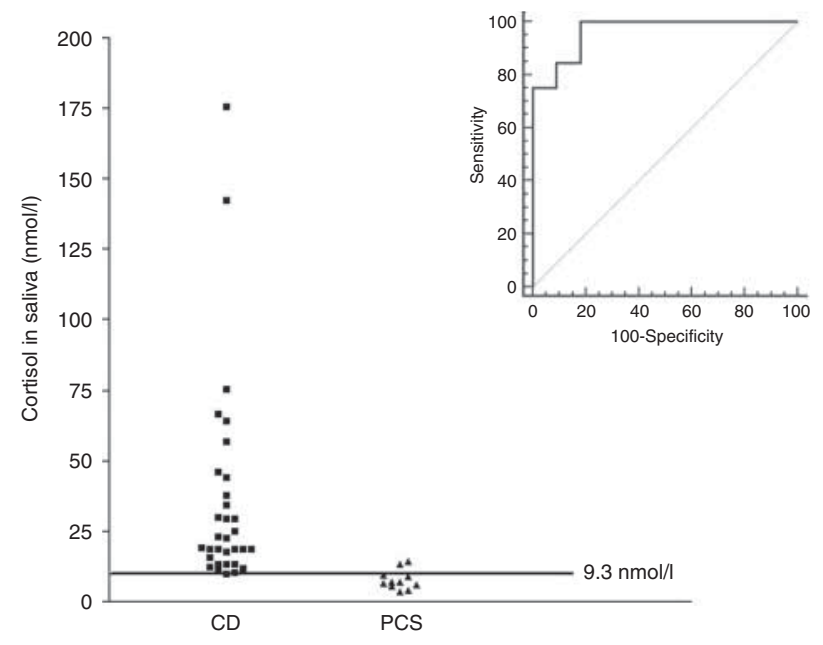

\section{Figure 3}

(Left) Dot diagram showing midnight cortisol levels in saliva of 33 patients with Cushing's disease (CD) and 11 patients with pseudo-Cushing's syndrome (PCS). (Right) Receiver operating characteristic (ROC) curve of the late-night cortisol measurement in saliva (LNSC). A threshold value of $9.3 \mathrm{nmol} / \mathrm{l}$ results in a positive predictive value of $94 \%$ to distinguish authentic $C D$ from PCS (negative predictive value 100\%, sensitivity $100 \%$, specificity $83 \%$, and area under ROC curve $=0.962$ ).
$50 \mathrm{nmol} / \mathrm{l}$ after 2 days of dexamethasone administration. The mean cortisol level after dexamethasone suppression and before $\mathrm{CRH}$ administration in the PCS group was $35 \mathrm{nmol} / \mathrm{l}$ ( \pm 3.0 ; range $27-78$ ).

Serum cortisol levels were higher than $50 \mathrm{nmol} / \mathrm{l}$ in 33/35 patients with CD after 2 days of dexamethasone suppression. The mean cortisol level after dexamethasone suppression (before CRH stimulation) in the CD group was $288 \mathrm{nmol} / \mathrm{l}( \pm 51$; range $28-1283)$. Using a cut-off value of $50 \mathrm{nmol} / \mathrm{l}$, this 2-day DST (without subsequent CRH stimulation) demonstrated a sensitivity of $94 \%$ and a specificity of 84\% (PPV 92\% and NPV 89\%).

Additional CRH stimulation (Dex-CRH test) led to a correct classification of three more patients with PCS (19/19). This resulted in a further improvement of the above-mentioned predictive values. The highest diagnostic accuracy of the Dex-CRH test was achieved when the serum cortisol concentration 15 min after CRH administration was used as the criterion. Patients with CD had significantly higher levels of CRH-stimulated serum cortisol than patients with PCS: $365 \pm 42.9$ vs $41 \pm$ $4.5 \mathrm{nmol} / \mathrm{l}(P<0.001)$. Measurement of plasma ACTH or serum cortisol at other time points did not improve the performance of the Dex-CRH test (data not shown).

The results of the Dex-CRH test are shown in Fig. 4. ROC curve analysis showed an optimal cut-off value of $87 \mathrm{nmol} / \mathrm{l}$ for CRH-stimulated serum cortisol at $T=15 \mathrm{~min}$ (sensitivity of 94\%, specificity 100\%, PPV 100\%, and NPV 90\%). The AUC provided by the ROC curve is 0.995 (Fig. 4).

\section{Mild hypercortisolism}

The diagnostic value of the described second-line tests did not significantly differ when only CD patients with mild hypercortisolism (i.e. UFC within two times the upper limit of normal; $n=28$ ) were compared with PCS patients (Table 2).

\section{Combined assessment of second-line tests}

Combined assessment of MserC concentration and Dex-CRH test was performed in 53 patients (35 CD and 18 PCS). The results of the two tests in these patients are plotted in Fig. 5. Discordant test results were found in four patients (Table 3 ).

Owing to the relatively small sample size of the PCS group in our study, a leave-one-out cross validation procedure failed to demonstrate any benefit of combining the results of the two second-line tests; the discriminatory 
Dexamethasone-CRH test

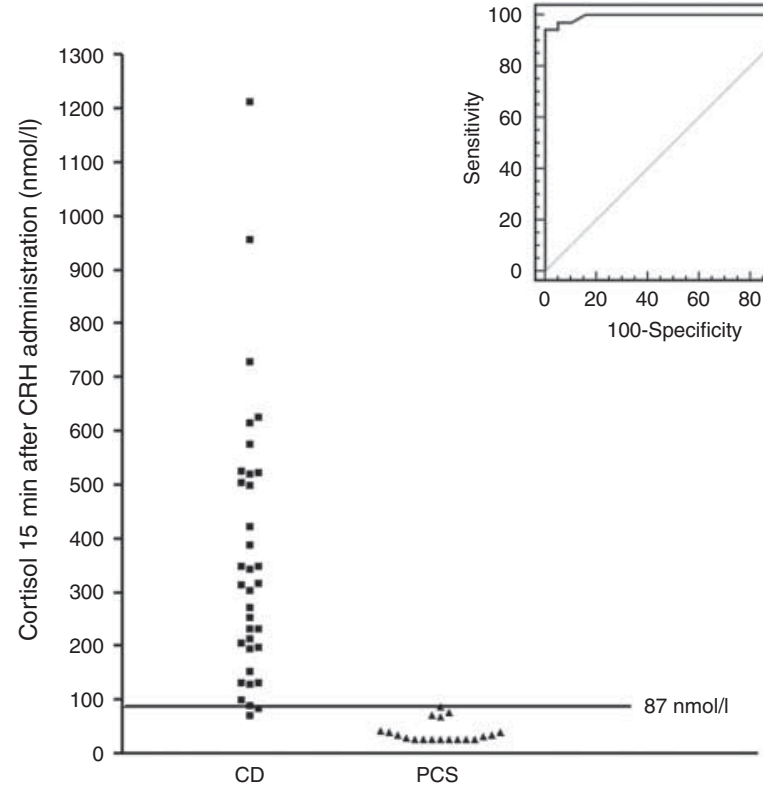

\section{Figure 4}

(Left) CRH-stimulated serum cortisol levels ( $T=15 \mathrm{~min}$ ) after dexamethasone suppression in 35 patients with Cushing's disease $(C D)$ and 19 patients with pseudo-Cushing's syndrome (PCS). (Right) Receiver operating characteristic (ROC) curve of the dexamethasone-CRH test. Optimal cut-off value for CRH-stimulated cortisol ( $T=15 \mathrm{~min}$ ) after dexamethasone suppression is $87 \mathrm{nmol} / \mathrm{l}$. Area under ROC curve is 0.995 (sensitivity $94 \%$, specificity $100 \%$, positive predictive value $100 \%$, and negative predictive value $90 \%$ ).

power of combined MserC and Dex-CRH testing was not superior compared with the predictive values of both individual tests.

\section{Discussion}

Distinguishing between PCS and (mild forms of) CD can be a diagnostic challenge. Different second-line tests have been used over the past years, but all of them have demonstrated limitations in diagnostic accuracy and it has not always been possible to replicate the proposed cut-off values. In addition, only a few studies have compared multiple tests within the same study population. The aim of our prospective study, therefore, was to validate four tests that are currently used to rule out PCS in a cohort of 73 patients with possible CD.

In normal subjects, cortisol is secreted episodically with a diurnal rhythm which parallels the secretion of
ACTH. Cortisol levels are highest upon awakening in the morning and decrease gradually throughout the day, reaching a nadir around midnight $(19,20)$. In most patients with CD, but not all, this cortisol diurnal rhythm is disrupted with loss of cortisol nadir at midnight due to continuous ACTH production by the corticotroph adenoma with no or less sensitivity to negative feedback suppression $(21,22,23,24)$. The diurnal profile of cortisol secretion is usually restored again after successful pituitary surgery in patients with CD (25). In our study, we assessed the profile of cortisol secretion during the day in patients with CD and patients with PCS. The CD group showed a relatively blunted cortisol secretion pattern throughout the day, whereas in the PCS group, the circadian rhythm of cortisol was preserved. The MserC concentration was more than $67 \%$ of the morning cortisol concentration in the majority of patients with CD (87\%). Using an optimal threshold value of 0.67 for the midnight:morning ratio of cortisol in serum, we found a PPV of $100 \%$. However, a relevant drawback of the analysis of the cortisol circadian rhythm in differentiating between CD and PCS is its low NPV (73\%), which may be attributed to a preserved cortisol diurnal rhythm in a subset of CD patients.

Table 2 Diagnostic accuracy of four different tests in patients with mild $\mathrm{CD}(n=28)$ and overt $\mathrm{CD}(n=25)$ compared with patients with pseudo-Cushing's syndrome $(n=20)$. Mild CD defined as UFC $\leq 2 \times$ upper limit of normal range. Overt $C D$ defined as UFC $>2 \times$ upper limit of normal range.

\begin{tabular}{|c|c|c|c|}
\hline & Mild CD & Overt CD & $\begin{array}{c}\text { All CD } \\
\text { (mild + } \\
\text { overt) }\end{array}$ \\
\hline \multicolumn{4}{|c|}{ Serum cortisol circadian rhythm } \\
\hline \multicolumn{4}{|c|}{ Midnight:morning ratio (cut-off 0.67 ) } \\
\hline Number of patients tested & 26 & 26 & 52 \\
\hline Sensitivity/specificity (\%) & $85 / 100$ & $89 / 100$ & $87 / 100$ \\
\hline PPV/NPV (\%) & $100 / 82$ & $100 / 86$ & $100 / 73$ \\
\hline \multicolumn{4}{|l|}{ MserC (cut-off 243 nmol/l) } \\
\hline Number of patients tested & 27 & 26 & 53 \\
\hline Sensitivity/specificity (\%) & $96 / 95$ & $100 / 95$ & $98 / 95$ \\
\hline PPV/NPV (\%) & 96/95 & $96 / 100$ & 98/95 \\
\hline \multicolumn{4}{|l|}{ LNSC (cut-off $9.3 \mathrm{nmol} / \mathrm{l}$ ) } \\
\hline Number of patients tested & 18 & 15 & 33 \\
\hline Sensitivity/specificity (\%) & $100 / 82$ & $100 / 82$ & $100 / 82$ \\
\hline PPV/NPV (\%) & $90 / 100$ & $88 / 100$ & $94 / 100$ \\
\hline \multicolumn{4}{|l|}{ Dex-CRH (cut-off $87 \mathrm{nmol} / \mathrm{l}$ ) } \\
\hline Number of patients tested & 21 & 14 & 35 \\
\hline Sensitivity/specificity (\%) & $90 / 100$ & $100 / 100$ & $94 / 100$ \\
\hline PPV/NPV (\%) & $100 / 90$ & $100 / 100$ & $100 / 90$ \\
\hline
\end{tabular}

$C D$, Cushing's disease; UFC, urinary free cortisol; MserC, midnight serum cortisol; LNSC, late-night salivary cortisol; Dex-CRH, dexamethasonecorticotropin-releasing hormone test; PPV, positive predictive value; NPV, negative predictive value. 


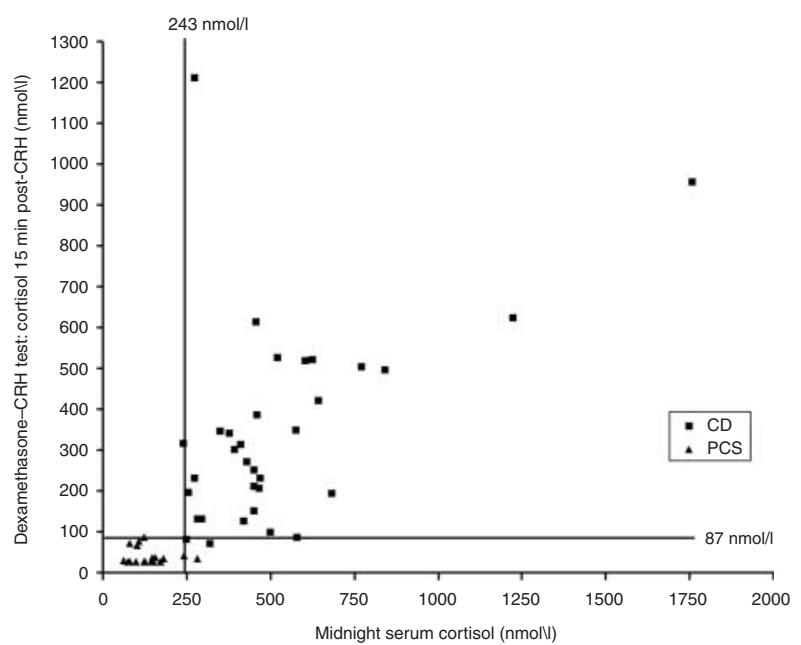

\section{Figure 5}

Combined results of the dexamethasone-CRH test and the single midnight serum cortisol measurement of 35 patients with Cushing's disease (CD) and 18 patients with pseudo-Cushing's syndrome (PCS). Vertical and horizontal lines denote the threshold values for the midnight serum cortisol concentration (243 nmol/l) and the dexamethasone-CRH test $(87 \mathrm{nmol} / \mathrm{l})$. Discordant results were found in four patients: three patients with CD and one patient with PCS (see also Table 3).

A number of studies have reported the utility of a single MserC measurement to correctly identify patients with PCS, with cut-off levels ranging from 207 to $331 \mathrm{nmol} / 1$ when sampled in the awake state $(9,14,16)$. According to our data, a single MserC concentration of $>243 \mathrm{nmol} / \mathrm{l}$ has a PPV of $98 \%$ in differentiating CD from PCS (NPV of 95\%). This high diagnostic accuracy is in accordance with other studies which used almost similar patient groups $(9,26)$. However, the impracticality and cost of admitting patients for MserC precludes the use of this test in the initial evaluation of patients with suspected hypercortisolism.
Cortisol levels in saliva correlate with levels of nonprotein bound cortisol in serum (i.e. biologically active circulating cortisol) and are independent of the salivary flow rate $(27,28)$. Previously described cut-off points for LNSC levels to establish the diagnosis of Cushing's syndrome vary from 2.95 to $15.2 \mathrm{nmol} / \mathrm{l}(6,16,29,30,31$, $32,33,34)$. This wide range can possibly be explained by differences in study design (prospective and retrospective), inclusion of different causes of Cushing's syndrome (pituitary, adrenal, and ectopic), the use of different control groups (healthy volunteers, patients with obesity, and PCS) and the use of different assays (RIAs, luminescence immunoassay, and mass spectrometry). We studied the usefulness of LNSC assessment in a cohort of patients with suspected hypercortisolism and non-suppressed ACTH levels in order to differentiate between true CD and PCS. We found an optimal threshold value of $9.3 \mathrm{nmol} / \mathrm{l}$ to differentiate between both entities with the assay used. Despite its high predictive values (PPV 94\% and NPV 100\%), determination of LNSC was not superior to MserC measurement in the current survey. However, an advantage of LNSC measurement is the fact that it is a simple and non-invasive method in the evaluation of patients with suspected hypercortisolism, and it is therefore increasingly used as first-line screening test. Salivary samples can be obtained in ambulatory patients and can be stored at room temperature for several days $(35,36,37)$. A potential concern when saliva sampling is performed at home is contamination with topical or inhaled steroids or collection of insufficient volumes of saliva. Other possible interfering factors are gingival bleeding or the stress of midnight awakening (38). Some authors therefore suggest the collection of two samples of saliva (during consecutive nights) when performed at home (39).

The combined Dex-CRH test was first introduced in 1993 (10). An excellent discrimination between CD and PCS was reported when using a serum cortisol cut-off value of $38 \mathrm{nmol} / 1$ at $15 \mathrm{~min}$ after CRH administration (PPV $100 \%$ and NPV 100\%). Later studies, however, indicated a

Table 3 Discordant results of the combined assessment of midnight serum cortisol level and Dex-CRH test.

\begin{tabular}{|c|c|c|c|c|c|c|}
\hline Patient no. & Gender & Age (years) & Diagnosis & $\begin{array}{c}\text { Follow-up } \\
\text { (months) }\end{array}$ & MserC $(\mathrm{nmol} / \mathrm{l})$ & Dex-CRH $(\mathrm{nmol} / \mathrm{l})$ \\
\hline 1 & $F$ & 80 & $C D$ & 80 & 317 & 72 \\
\hline 2 & $\mathrm{~F}$ & 74 & $C D$ & 50 & 246 & 84 \\
\hline 3 & $\mathrm{~F}$ & 24 & $C D$ & 12 & 237 & 317 \\
\hline 4 & $M$ & 66 & PCS & 35 & 281 & 35 \\
\hline
\end{tabular}

$\mathrm{CD}$, Cushing's disease; PCS, pseudo-Cushing's syndrome; MserC, midnight serum cortisol concentration; Dex-CRH, CRH-stimulated cortisol level ( $T=15 \mathrm{~min}$ ) during dexamethasone-CRH test. 
lower diagnostic performance of the test (PPV 80-86\% and NPV 92-100\%) and proposed different threshold values for the 15 -min post-CRH cortisol concentration $(44-110 \mathrm{nmol} / \mathrm{l})(13,14,15,17)$. These findings are confirmed in the present survey, as we found an optimal threshold value of $87 \mathrm{nmol} / \mathrm{l}$ for serum cortisol $15 \mathrm{~min}$ after CRH administration (PPV 100\% and NPV 90\%). The 2-day DST (2 days of dexamethasone suppression without CRH stimulation) also performed reasonably well (cut-off $50 \mathrm{nmol} / \mathrm{l}$; PPV 92\% and NPV 89\%), but both its PPV as well as its NPV further increased after adding CRH stimulation, although these results are based on a relatively small sample size. In contrast, a study conducted by Martin et al. showed no improvement in the diagnostic accuracy of the 2-day DST when CRH was administered additionally. However, compared with our survey, there was a significant difference in the inclusion of patients with Cushing's syndrome (pituitary and adrenal vs pituitary only) and the number of dexamethasone doses (nine vs eight) (15).

Differences in reliability of the Dex-CRH test in the above-mentioned studies can possibly be explained by the use of different protocols for the Dex-CRH test, administration of different CRH preparations (ovine or human), differences in CRH dosage $(1 \mu \mathrm{g} / \mathrm{kg}$ or $100 \mu \mathrm{g})$, variation in cortisol and ACTH assays, in particular with respect to measurements in the low range, and absence of uniform criteria to define PCS. Despite the fact that the test is relatively expensive and impractical (hospital admission is required), the Dex-CRH test, based on its relatively high diagnostic accuracy, can still be a valuable tool in cases with indeterminate results of first-line screening tests.

Because it is most difficult to differentiate between CD and PCS in patients with mild ACTH-dependent hypercortisolism, a clinically relevant observation in our study is that the diagnostic performance of all evaluated tests was not different when CD patients with UFC levels within two times the upper limit of normal were compared with PCS patients.

Combining second-line tests did not improve diagnostic accuracy, possibly due to the relatively small sample size of the PCS group. As always, when more tests are used, discrepancies between test results can occur. Generally, within individual patients, the different tests used indicated the same diagnosis. We found in only four patients $(\mathrm{CD}=3$ and $\mathrm{PCS}=1)$ discrepancies between MserC and post Dex-CRH-stimulated cortisol levels which were just below or above the cut-off value and i.e. because they demonstrated a corticotroph adenoma with positive ACTH staining, these patients cannot be classified. In the clinical scenario where test results are discordant in a patient with mild hypercortisolism, followup is recommended for monitoring progression of symptoms and for repeat testing (1).

ACTH-secreting pituitary adenomas are known to show overexpression of receptors for $\mathrm{CRH}$ and vasopressin in corticotroph cells. Stimulation with either CRH or desmopressin, a synthetic vasopressin analog, results in a direct release of ACTH $(40,41,42)$. Tirabassi et al. (43) reported excellent diagnostic performance as well as perfect diagnostic agreement for the human CRH test and the desmopressin test in a study with a small number of patients with PCS $(n=12)$, which should be confirmed by future studies.

The strength of our current survey is its prospective design and the clear biochemical criteria used to define PCS (abnormal result in DST and/or elevated UFC on at least two occasions). The limitations are UFC measurement without solvent extraction, the relatively small number of PCS patients, no measurement of plasma dexamethasone levels during DST and Dex-CRH testing and the fact that not all tests were performed in all participating patients.

\section{Conclusion}

In the present study, the Dex-CRH test as well as measurement of cortisol in saliva or serum collected at midnight showed high diagnostic accuracy in distinguishing between true CD and PCS. Results of the different tests were concordant in most patients and combining tests did not increase the diagnostic yield. Considering its convenience, its high diagnostic accuracy as a first-line screening test as well as its ability to differentiate between $\mathrm{CD}$ and PCS, the use of midnight salivary cortisol assessment as a first-choice test seems rational. Depending on the protocol and assay(s) used, it is important for diagnostic centers to validate these tests and their threshold values.

\section{Declaration of interest}

A J van der Lely is a consultant for Novartis Pharma, Pfizer International, and Ipsen Pharma International. W W de Herder is a consultant for Novartis Pharma and Ipsen Pharma International. R A Feelders is a consultant for Novartis Pharma. The other authors have nothing to disclose.

\section{Funding}

This research did not receive any specific grant from any funding agency in the public, commercial or not-for-profit sector. 


\section{References}

1 Nieman LK, Biller BM, Findling JW, Newell-Price J, Savage MO, Stewart PM \& Montori VM. The diagnosis of Cushing's syndrome: an Endocrine Society Clinical Practice Guideline. Journal of Clinical Endocrinology and Metabolism 200893 1526-1540. (doi:10.1210/jc. 2008-0125)

2 Newell-Price J, Trainer P, Besser M \& Grossman A. The diagnosis and differential diagnosis of Cushing's syndrome and pseudo-Cushing's states. Endocrine Reviews 199819 647-672.

3 Kamenicky P, Droumaguet C, Salenave S, Blanchard A, Jublanc C, Gautier JF, Brailly-Tabard S, Leboulleux S, Schlumberger M, Baudin E et al. Mitotane, metyrapone, and ketoconazole combination therapy as an alternative to rescue adrenalectomy for severe ACTH-dependent Cushing's syndrome. Journal of Clinical Endocrinology and Metabolism 201196 2796-2804. (doi:10.1210/jc.2011-0536)

4 Lindholm J, Juul S, Jorgensen JO, Astrup J, Bjerre P, Feldt-Rasmussen U, Hagen C, Jorgensen J, Kosteljanetz M, Kristensen L et al. Incidence and late prognosis of Cushing's syndrome: a population-based study. Journal of Clinical Endocrinology and Metabolism 200186 117-123.

5 Gafni RI, Papanicolaou DA \& Nieman LK. Nighttime salivary cortisol measurement as a simple, noninvasive, outpatient screening test for Cushing's syndrome in children and adolescents. Journal of Pediatrics 2000137 30-35. (doi:10.1067/mpd.2000.106226)

6 Raff H, Raff JL \& Findling JW. Late-night salivary cortisol as a screening test for Cushing's syndrome. Journal of Clinical Endocrinology and Metabolism 199883 2681-2686.

7 Alexandraki KI \& Grossman AB. Is urinary free cortisol of value in the diagnosis of Cushing's syndrome? Current Opinion in Endocrinology, Diabetes, and Obesity 201118 259-263. (doi:10.1097/MED. Ob013e3283487193)

8 Crapo L. Cushing's syndrome: a review of diagnostic tests. Metabolism 197928 955-977. (doi:10.1016/0026-0495(79)90097-0)

9 Papanicolaou DA, Yanovski JA, Cutler GB Jr, Chrousos GP \& Nieman LK. A single midnight serum cortisol measurement distinguishes Cushing's syndrome from pseudo-Cushing states. Journal of Clinical Endocrinology and Metabolism 199883 1163-1167.

10 Yanovski JA, Cutler GB Jr, Chrousos GP \& Nieman LK. Corticotropinreleasing hormone stimulation following low-dose dexamethasone administration. A new test to distinguish Cushing's syndrome from pseudo-Cushing's states. Journal of the American Medical Association 1993269 2232-2238. (doi:10.1001/jama.1993.03500170062035)

11 Castro M \& Moreira AC. Screening and diagnosis of Cushing's syndrome. Arquivos Brasileiros de Endocrinologia e Metabologia 200751 1191-1198.

12 Jacobson L. Hypothalamic-pituitary-adrenocortical axis regulation. Endocrinology and Metabolism Clinics of North America 200534 271-292 (vii). (doi:10.1016/j.ecl.2005.01.003)

13 Erickson D, Natt N, Nippoldt T, Young WF Jr, Carpenter PC, Petterson T \& Christianson T. Dexamethasone-suppressed corticotropin-releasing hormone stimulation test for diagnosis of mild hypercortisolism. Journal of Clinical Endocrinology and Metabolism 200792 2972-2976.

14 Gatta B, Chabre O, Cortet C, Martinie M, Corcuff JB, Roger P \& Tabarin A. Reevaluation of the combined dexamethasone suppression-corticotropin-releasing hormone test for differentiation of mild Cushing's disease from pseudo-Cushing's syndrome. Journal of Clinical Endocrinology and Metabolism 200792 4290-4293. (doi:10.1210/jc.2006-2829)

15 Martin NM, Dhillo WS, Banerjee A, Abdulali A, Jayasena CN, Donaldson M, Todd JF \& Meeran K. Comparison of the dexamethasone-suppressed corticotropin-releasing hormone test and low-dose dexamethasone suppression test in the diagnosis of Cushing's syndrome. Journal of Clinical Endocrinology and Metabolism 200691 2582-2586. (doi:10.1210/jc.2005-2143)

16 Putignano P, Toja P, Dubini A, Pecori Giraldi F, Corsello SM \& Cavagnini F. Midnight salivary cortisol versus urinary free and midnight serum cortisol as screening tests for Cushing's syndrome. Journal of Clinical Endocrinology and Metabolism 200388 4153-4157. (doi:10.1210/jc.2003-030312)

17 Reimondo G, Bovio S, Allasino B, De Francia S, Zaggia B, Micossi I, Termine A, De Martino F, Paccotti P, Di Carlo F et al. The combined low-dose dexamethasone suppression corticotropin-releasing hormone test as a tool to rule out Cushing's syndrome. European Journal of Endocrinology 2008 159 569-576. (doi:10.1530/ EJE-08-0402)

18 Croughs RJ, Docter R \& de Jong FH. Comparison of oral and intravenous dexamethasone suppression tests in the differential diagnosis of Cushing's syndrome. Acta Endocrinologica 197372 54-62.

19 Krieger DT, Allen W, Rizzo F \& Krieger HP. Characterization of the normal temporal pattern of plasma corticosteroid levels. Journal of Clinical Endocrinology and Metabolism 1971 32 266-284. (doi:10.1210/ jcem-32-2-266)

20 Weitzman ED, Fukushima D, Nogeire C, Roffwarg H, Gallagher TF \& Hellman L. Twenty-four hour pattern of the episodic secretion of cortisol in normal subjects. Journal of Clinical Endocrinology and Metabolism 197133 14-22. (doi:10.1210/jcem-33-1-14)

21 Krieger DT \& Allen W. Relationship of bioassayable and immunoassayable plasma ACTH and cortisol concentrations in normal subjects and in patients with Cushing's disease. Journal of Clinical Endocrinology and Metabolism 197540 675-687.

22 Roelfsema F, Pincus SM \& Veldhuis JD. Patients with Cushing's disease secrete adrenocorticotropin and cortisol jointly more asynchronously than healthy subjects. Journal of Clinical Endocrinology and Metabolism 199883 688-692.

23 van den Berg G, Pincus SM, Veldhuis JD, Frolich M \& Roelfsema F. Greater disorderliness of ACTH and cortisol release accompanies pituitary-dependent Cushing's disease. European Journal of Endocrinology 1997136 394-400. (doi:10.1530/eje.0.1360394)

24 van der Pas R, de Bruin C, Pereira AM, Romijn JA, Netea-Maier RT, Hermus AR, Zelissen PM, de Jong FH, van der Lely AJ, de Herder WW et al. Cortisol diurnal rhythm and quality of life after successful medical treatment of Cushing's disease. Pituitary 201316 536-544. (doi:10.1007/s11102-012-0452-2)

25 Veldman RG, Frolich M, Pincus SM, Veldhuis JD \& Roelfsema F. Apparently complete restoration of normal daily adrenocorticotropin, cortisol, growth hormone, and prolactin secretory dynamics in adults with Cushing's disease after clinically successful transsphenoidal adenomectomy. Journal of Clinical Endocrinology and Metabolism 2000 85 4039-4046.

26 Reimondo G, Allasino B, Bovio S, Paccotti P, Angeli A \& Terzolo M. Evaluation of the effectiveness of midnight serum cortisol in the diagnostic procedures for Cushing's syndrome. European Journal of Endocrinology 2005153 803-809. (doi:10.1530/eje.1.02042)

27 Umeda T, Hiramatsu R, Iwaoka T, Shimada T, Miura F \& Sato T. Use of saliva for monitoring unbound free cortisol levels in serum. Clinica Chimica Acta 1981110 245-253. (doi:10.1016/0009-8981(81)90353-3)

28 Walker RF, Riad-Fahmy D \& Read GF. Adrenal status assessed by direct radioimmunoassay of cortisol in whole saliva or parotid saliva. Clinical Chemistry 197824 1460-1463.

29 Deutschbein T, Broecker-Preuss M, Flitsch J, Jaeger A, Althoff R, Walz MK, Mann K \& Petersenn S. Salivary cortisol as a diagnostic tool for Cushing's syndrome and adrenal insufficiency: improved screening by an automatic immunoassay. European Journal of Endocrinology 2012 166 613-618. (doi:10.1530/EJE-11-0945)

30 Manetti L, Rossi G, Grasso L, Raffaelli V, Scattina I, Del Sarto S, Cosottini M, Iannelli A, Gasperi M, Bogazzi F et al. Usefulness of salivary cortisol in the diagnosis of hypercortisolism: comparison with serum and urinary cortisol. European Journal of Endocrinology 2013168 315-321. (doi:10.1530/EJE-12-0685)

31 Papanicolaou DA, Mullen N, Kyrou I \& Nieman LK. Nighttime salivary cortisol: a useful test for the diagnosis of Cushing's syndrome. 
Journal of Clinical Endocrinology and Metabolism 200287 4515-4521. (doi:10.1210/jc.2002-020534)

32 Sakihara S, Kageyama K, Oki Y, Doi M, Iwasaki Y, Takayasu S, Moriyama T, Terui K, Nigawara T, Hirata Y et al. Evaluation of plasma, salivary, and urinary cortisol levels for diagnosis of Cushing's syndrome. Endocrine Journal 201057 331-337. (doi:10.1507/endocrj. K09E-340)

33 Yaneva M, Mosnier-Pudar H, Dugue MA, Grabar S, Fulla Y \& Bertagna X. Midnight salivary cortisol for the initial diagnosis of Cushing's syndrome of various causes. Journal of Clinical Endocrinology and Metabolism 200489 3345-3351. (doi:10.1210/jc.2003-031790)

34 Zerikly RK, Amiri L, Faiman C, Gupta M, Singh RJ, Nutter B, Kennedy L, Hatipoglu B, Weil RJ \& Hamrahian AH. Diagnostic characteristics of late-night salivary cortisol using liquid chromatography-tandem mass spectrometry. Journal of Clinical Endocrinology and Metabolism 201095 4555-4559. (doi:10.1210/jc.2009-2458)

35 Chen YM, Cintron NM \& Whitson PA. Long-term storage of salivary cortisol samples at room temperature. Clinical Chemistry 199238304.

36 Garde AH \& Hansen AM. Long-term stability of salivary cortisol. Scandinavian Journal of Clinical and Laboratory Investigation 200565 433-436. (doi:10.1080/00365510510025773)

37 Mosnier-Pudar H, Thomopoulos P, Bertagna X, Fournier C, Guiban D \& Luton JP. Long-distance and long-term follow-up of a patient with intermittent Cushing's disease by salivary cortisol measurements. European Journal of Endocrinology 1995133 313-316. (doi:10.1530/eje.0. 1330313)
38 Raff H. Salivary cortisol and the diagnosis of Cushing's syndrome: a coming of age. Endocrine 201241 353-354. (doi:10.1007/s12020-012-9661-8)

39 Carrasco CA, Garcia M, Goycoolea M, Cerda J, Bertherat J, Padilla O, Meza D, Wohllk N \& Quiroga T. Reproducibility and performance of one or two samples of salivary cortisol in the diagnosis of Cushing's syndrome using an automated immunoassay system. Endocrine $2012 \mathbf{4 1}$ 487-493. (doi:10.1007/s12020-012-9597-z)

40 Luque R, Ibanez-Costa A, Lopez-Sanchez L, Jimenez-Reina L, VenegasMoreno E, Galvez M, Villa-Osaba A, Madrazo-Atutxa A, Japon M, de la Riva A et al. A cellular and molecular basis for the selective desmopressin-induced ACTH release in Cushing's disease patients: key role of AVPR1b receptor and potential therapeutic implications. Journal of Clinical Endocrinology and Metabolism 201398 4160-4169. (doi:10.1210/jc.2013-1992)

41 Newell-Price J, Perry L, Medbak S, Monson J, Savage M, Besser M \& Grossman A. A combined test using desmopressin and corticotropinreleasing hormone in the differential diagnosis of Cushing's syndrome. Journal of Clinical Endocrinology and Metabolism 199782 176-181.

42 Sakai Y, Horiba N, Tozawa F, Sakai K, Kuwayama A, Demura H \& Suda T. Desmopressin stimulation test for diagnosis of ACTH-dependent Cushing's syndrome. Endocrine Journal 199744 687-695. (doi:10.1507/ endocrj.44.687)

43 Tirabassi G, Papa R, Faloia E, Boscaro M \& Arnaldi G. Corticotrophinreleasing hormone and desmopressin tests in the differential diagnosis between Cushing's disease and pseudo-Cushing state: a comparative study. Clinical Endocrinology 201175 666-672. (doi:10.1111/j.13652265.2011.04096.x)

Received 24 August 2013

Revised version received 15 December 2013

Accepted 6 January 2014 